Article

\title{
Young People Collecting Natural Souvenirs: A Perspective of Sustainability and Marketing
}

\author{
Arnold Pabian*, Aleksander Pabian and Andrzej Brzeziński \\ Department of Management, Czestochowa University of Technology, 42-201 Częstochowa, Poland; \\ aleksander.pabian@hotmail.com (A.P.); abf@op.pl (A.B.) \\ * Correspondence: arnold.p@wp.pl
}

Received: 19 December 2019; Accepted: 8 January 2020; Published: 9 January 2020

\begin{abstract}
Collecting of natural souvenirs causes destruction of the natural environment as well as social and economic problems. The article shows that the next generation will have a tendency to aggravate such problems by collecting natural souvenirs. To discover the preferences of young people related to collecting natural souvenirs, the authors performed a survey in Poland on a sample of 426 persons aged $21-30$. The survey has shown that $80.7 \%$ of young people participating in tourist trips bring souvenirs to their places of residence. As much as $61.4 \%$ collect natural souvenirs. Most people bring shells $(53.9 \%)$, rocks $(22.7 \%)$, and sand from seaside beaches $(18.0 \%)$. Natural souvenirs are important to young Poles. This is confirmed by the following major motivations for collection: natural souvenirs are unique $(26.2 \%)$, genuine $(23.8 \%)$, bring back the best memories $(22.6 \%)$, and cannot be bought in stores (14.5\%). Only $9.8 \%$ of those surveyed oppose bringing of natural souvenirs, $5.2 \%$ deem such practices unlawful, and $11.2 \%$ recognize their detrimental effect on local tourist attractions. The article presents demarketing actions, which can largely stem the negative phenomenon of collection of natural souvenirs.
\end{abstract}

Keywords: sustainability; sustainable tourism; natural souvenirs; demarketing

\section{Introduction}

Sustainable development cannot keep up with the pace and scale of accumulation of ecological problems. The natural potential of the Earth is quickly running low. The aggravating unsustainability is evidenced by the deteriorating indicators presented in subsequent editions of the Living Planet Report. The global equilibrium between the Earth's ecosystems, which have developed for millions of years, and the human world of production and consumption, becomes disrupted. Not only do these ecosystems provide humans with food, water, and fresh air, but they also create the conditions for relax needed by every tourist.

The concept of sustainability has entered the sector of tourism, initiating the development of sustainable tourism, also known as soft tourism or environmentally sensible tourism. Today, sustainable tourism is regarded as a broadly understood concept of environmentally-friendly tourist development in rural areas and in cities, in small tourist centres, as well as great entertainment and leisure centres. It means respect to cultural, social, and natural values of the area visited by the tourists; protection of natural and cultural resources; respect to the identity, tradition, and lifestyle of local communities, with simultaneous utilization (primarily by the local community, to a smaller extent by external investors) of an economic opportunity provided by tourism for the economic development of the region. Sustainable tourism relies on the model of sustainable development, which was first defined in a declaration of the UN convention (1972), and finally clarified in 1987 by the World Commission on Environment and Development in the report "Our Common Future". 
Although the interest in sustainable tourism among both researchers and tourism organizers is on the rise, the same cannot be said about travel agency customers. The behaviours of many tourists are still contrary to this idea. An example can be taking of natural souvenirs, i.e., various elements of natural environment, fauna, flora, urban, and rural architecture, such as sand, stones, shells, parts of walls, from places of leisure. Tourists from all around the world appropriate different objects during their holidays, including sand, gravel, stones, shells, parts of volcanic rocks, parts of plants, or even small animals. During a single summer season, customs services at the Cagliari airport can confiscate as much as five tons of sand from the tourists. Azulejo tiles disappear from Portugal. In St. Petersburg, in the city centre alone, 12,000 cobblestones vanish from the Palace Square each year. There are willing buyers for pieces of the Berlin Wall as well [1]. Unfortunately, in the age of mass travelling, such practices are contrary to the principles of sustainable development. They exemplify activities from the area of warped tourism, characterized by a destructive effect on all three spheres of the system, i.e., the natural environment, the socio-cultural environment and the economy itself.

Tourists collect natural souvenirs during domestic and foreign trips and then bring them to their places of residence. Such practices result in emergence of research problems regarding the attitude of young people to bringing natural souvenirs and the legality of such practices in their opinion, the consequences for the natural and cultural environment as well as for the society and the economy, the kinds of natural souvenirs brought by young tourists, the tendency by young generation to aggravate or eliminate ecological problems arising from acquisition of natural souvenirs.

In order to explain these problems, the authors of the article performed a questionnaire survey on a representative group of 420 persons aged 21-30, participating in tourist trips. The goal of the article is to present the survey results together with conclusions, as well as to formulate marketing recommendations the implementation of which may largely reduce the damage caused by bringing of natural souvenirs. This will have a favourable effect on the condition of the natural environment, and will protect cultural heritage, including monuments of history, from destruction, largely contributing to sustainable development.

The problem of collecting natural souvenirs is very important and should be investigated in various aspects. Modern tourism is a mass phenomenon. Most tourists bring souvenirs (natural ones as well) from their trips. Therefore, collecting natural souvenirs is becoming a mass phenomenon as well. This means mass depletion and destruction, primarily of the natural environment of which humans are a part. It also causes social and economic problems. In this context, the preferences and behaviors of the young people are important. The young generation takes over responsibility of the Earth and will influence the future of the world.

\section{Literature Review}

Many scholars have studied the subject matter of tourist souvenirs, identifying them with messengers of meaning and tradable commodities (historical perspectives on souvenirs research, souvenirs as messengers of meaning, souvenirs as tradable commodities and the commodification of souvenirs and handicrafts) [2]. Researchers agree that every souvenir is a thing representing the environment of a destination, affecting a person. In the age of mass consumption, travel souvenirs usually function as a part of supply of the tourist market, comprising products of the souvenir industry or craft with exchange and utility value. The most popular tourist souvenirs are objects specially made for sale, including different utility objects, toys, local and regional products, foods, signs and symbols, presenting the culture of the destination. An important group of souvenirs is comprised by photographs and videos made by tourists themselves. Yet another group includes objects which gain the status of souvenirs by decision of the tourists. This means products which have not been made for tourist purposes but in order to satisfy the needs of local purchasers, e.g., beer coasters [3-5]. From a sociological perspective, it is important to define souvenirs as commodities with specific values, such as Marx's use and exchange value and Baudrillard's sign-value, as well as introducing an additional one, the spiritual-value, as well as functions the tourist expects to obtain by purchasing them [6]. 
Souvenirs are perceived not only by their utility, but also by their meaningfulness [7]. They fit into the duality of the sphere of cultural meanings, pointed out by C. Geertz. They speak of something, constitute a model of something, and invoke something at the same time (adapting the reality to themselves), thus constituting the so-called model for themselves. This fact is confirmed by the research of Michael Haldrup who has pointed out the roles they take as material and embodied cohabitants in domestic space, living and communicating with their owners. Therefore, a souvenir is not only a tourist marker or a personal object of memory but it has many faces as a utility item, mediator, fetish, tuner, and artwork [8]. The attitude of people to souvenirs is identical as to things in Löfgren's approach. People do not only look at them but also get addicted to them, use them, wear them, destroy them, repair them, get bored with them, discard them, sometimes to recover them at a later point [9].

A souvenir also expresses the wish to search for authenticity. This is not just about the reality of its appearance but also the authenticity of origin. Noga Collins-Kreiner, Yael Zins [10] point out that souvenirs which have not been purchased at a store or stall remind tourists of their travel. They are objects of idealized reality, substituting for places visited by the tourists during their trip. As research in Laos has shown that authentic souvenirs need to integrate culture and history to represent place identity of the destination, to be handmade, to have a unique, attractive presentation and to require local-specific skills of local artisans [11]. Criteria used by tourists from Midwestern US to define authenticity included craft uniqueness, workmanship, aesthetics and use, cultural and historical integrity, and genuineness; characteristics of the craftperson and the shopping experience also contributed to authenticity [12].

A recent study on souvenirs is a book edited by M. Hitchcock and K. Teague [13]. Authors begin from explanation of the concept of souvenirs and clarification of the essential conceptual framework in this regard. Simultaneously, they define this term in rather general, broad categories: "souvenirs, broadly conceived, are generally thought to be the material counterpart of travels, events, relationships and memories of all kind". Furthermore, they do not focus on physical aspects connected with objects of memory: "do not necessarily focus on material souvenirs in their memorial function as souvenirs". In the next subchapters of the study, they rather utilize case studies as an introduction to discussions of the meaning of souvenirs to those who bring them: "a key focus of many of these chapters, indeed of any discussion of souvenirs, is the question of meaning: what is the meaning of any particular souvenir or collection, and for whom does it bear the meaning?" They recapitulate the results of their discussion with an observation that "for the individual owner, the importance of the souvenir is the memorial link with some occasion, usually an occasion centring on a person or place. The meaning of a souvenir object may be more than just its souvenir function. The owner may value it for some other reason, e.g., home décor, monetary value, or class or status maker". They draw such conclusions based on analysis of experiences connected with acquisition of souvenir objects from destinations as diverse as Santiago de Compostela, the Japanese island of Hokkaido, or Kambot (Papua New Guinea). A completely different approach is represented by D. L. Hume in Tourism Art and Souvenirs [14]. Unlike the authors quoted before, D. L. Hume focuses on physical aspects of souvenirs, and specifically, broadly discusses the issues related to their artistic advantages: "this book examines the relationship between art and tourism through the study of the material culture of tourism: tourist art and souvenirs. It thoroughly examines how to categorise the material culture of tourism within the discourses of contemporary art and cultural anthropology, and demonstrates that tourist art is a unique expression of place and genuine artistic style".

The researches also investigated issues with regard to sustainable attitudes of young tourists. Han, Heesup; Kiatkowskin, Kiattipoom; Ryu, Hyungseo Bobby; Jung, Heekyoung; Kim, Wansoo [15] discovered that environmental values, concern, and awareness contribute to the generation of young vacationers' intention to engage in recycling and to conserve water, energy, and local resources at a destination. Heesup Han, Jongsik Yu, Hyeon-Cheol Kim, and Wansoo Kim [16] investigated the associations among social norms (descriptive and injunctive), willingness to sacrifice, and personal norm by developing a theoretical framework for young vacationers' waste reduction and recycling 
intentions. According to Heesup Han, Wansoo Kim, and Kiattipoom Kiatkawsin [17], greening is one of the most important issues faced by the tourism industry today. Their study developed a conceptual framework involving biospheric value, environmental concern, environmental awareness, ascribed responsibility, and moral norm in order to better explain young travelers' pro-environmental decision-making process. Bo Meng, Hyungseo Bobby Ryu, Bee-Lia Chua, and Heesup Han [18] write that volunteer tourism (VT) is an emerging tourism paradigm especially for young tourists. Trust, attitude, and subjective norm played important roles in this sphere.

Despite the presence of books on souvenirs as such on the publishing market, there is a lack of studies strictly focused on so-called natural souvenirs. There are no studies dedicated strictly to natural souvenirs, i.e., those not purchased, but comprising a part of the landscape. Some vestigial information, e.g., on shell products as souvenirs, may be found not so much in literature on tourism as in literature connected with issues of ecology and environmental protection, such as the annual report: Solomon Islands. Ecology, Nature Protection Laws and Regulations Handbook, International Business Publications, Washington 2011. Therefore, it is necessary to fill the observed research gap. The authors devote the following chapters of the study to this subject matter.

Regardless of whether they are mass-produced commodities, goods manufactured elsewhere or local handicrafts, souvenirs are static objects, unable to intermediate or to generate co-created, active or absorbing experiences wanted by tourists. The development of additive production (3D printing) and open digital production devices create possibilities for customization, creativity, and prosumption, which could alter the consumption of souvenirs [19]. They could also eliminate the phenomenon of acquisition of natural souvenirs regarded as authentic and creative. Similarly, this phenomenon could be eliminated by appropriately supplied souvenir stores that should provide the customers with a unique, broad assortment of souvenirs [20]. In addition to the attributes of the souvenirs and attributes of the store, the kind of souvenirs brought is affected by motivations for travel. Therefore, the goal is to provide a pleasant and profitable sales environment, to the benefit of both the tourist and the economy [21].

\section{Research Method}

In the light of the previous discussion, a research problem emerges concerning whether the young generation of tourists has a tendency for aggravation or for mitigation of ecological, social, and economic problems caused by acquisition of natural souvenirs. From the scientific perspective, it is relevant not just to describe the phenomenon but, above all, to interpret it in the prognostic aspect (indication how the young generation to follow us will affect the state of unsustainability through their practices concerning natural souvenirs) and in the utilitarian aspect, i.e., explanation what benefits to the natural environment, society, and economy will be brought by elimination of this phenomenon.

Before proceeding with the research, the main goal and specific research goals were formulated. The main goal was to identify the existing trends with regard to bringing of natural souvenirs by the young generation of tourists in the aspect of sustainable development and sustainable tourism, and to determine on this basis how such practices may affect sustainable development. The specific goals were formulated as follows:

1. determination of the scale of the phenomenon of bringing of natural souvenirs by young tourists;

2. identification of motivations for bringing of natural souvenirs;

3. determination of what natural souvenirs are most preferably brought by young tourists from their trips;

4. determination of what happens to natural souvenirs after young tourists return to their place of residence;

5. collection of opinions concerning bringing of natural souvenirs, the lawfulness of such practices, and the environmental damage; 
6. determination of the kinds of damages to the natural, social, and economic environment, resulting from acquisition of natural souvenirs;

7. determination of manners of elimination of hazards caused by acquisition of natural souvenirs.

Before proceeding with the survey, its project was developed. The first phase of the survey was the method of analysis and criticism of literature, which proved the purposefulness and originality of the examined research problems (bibliographic query, at-desk research). For the purpose of survey, a research tool in the form of a questionnaire was developed, the minimum sample size was determined, and the manner of communication with the respondents was specified. Having conducted the field study, its results were listed and analysed and conclusions were formulated.

Achievement of the determined research goal was possible thanks to a study conducted using a representational method, which had been considered the most proper form of partial research. Random selection of individuals enabled obtaining of a sample as similar as possible to the population. This procedure became a basis for estimation of population property based on sample property.

Four hundred and twenty-six people were subject to the survey process. Such a number of respondents meets the assumptions of a minimum sample size. The minimum sample size was determined in order to draw conclusions about the surveyed population, characterized by specific accuracy and degree of certainty, on the basis of the conducted measurements. When determining the necessary sample size, the following steps were taken:

- estimation accuracy was determined, assuming a specific maximum error of estimate;

- a high confidence level was assumed;

- $\quad$ assumptions concerning the proportion of the surveyed population were made.

Assuming that the success probability order of magnitude $p$ is unknown, the minimum number of individuals was 385 at the following assumptions: significance level $\alpha=0.05$, maximum error of estimate $d=5 \%\left(u_{\alpha}=1.959964\right)$.

The survey was conducted among 426 persons. Since the bringing of natural souvenirs is inseparably connected with tourist trips, only those respondents who participate in tourist trips had to be selected from this group. In order to implement this task, the following question was included in the beginning of the questionnaire: How often do you travel for tourist purposes? There were answer variants: several times per year, once per year, once per several years, I do not travel. The analysis of answers to this question enabled people who do not travel as tourists, so they cannot bring any souvenirs, including natural ones, to be excluded from the further research. Six respondents ( 3 women and 3 men) turned out not to travel as tourists. Ultimately, the survey covered 420 people, i.e., only those who had participated in tourist trips. They included 291 women and 129 men. The research tool was a survey questionnaire. The survey form consisted of two parts. The first part contained questions aimed at solving the research problem regarding collecting natural souvenirs by young tourists. The questions included in the survey were both closed-response questions and open-response questions. It was important to make sure that the questionnaire met the researchers' expectations in terms of the information needed. Therefore, a questionnaire pretest was made. The second part of the questionnaire explained how old the respondent was and what gender he represented. The survey was anonymous. The respondents were contacted personally.

\section{Empirical Results}

All participants of the survey had participated in tourist trips. The frequency of tourist trips of the surveyed group was as follows: $48.8 \%$ of respondents engage in tourist trips several times per year, $42.8 \%$ leave once per year, whereas $8.4 \%$ participate in tourist trips once per several years.

The survey has shown that most people ( $47.6 \%)$ engage in both domestic and foreign tourism; $43.1 \%$ of respondents focus exclusively on domestic tourism. Foreign tourism alone is preferred by $9.3 \%$ of the surveyed. 
The further part of the study has explained the attitude of the respondents to bringing of souvenirs from tourist trips. $80.7 \%$ of tourists turned out to bring souvenirs from their trips. $19.3 \%$ of the surveyed do not do this.

The following three issues addressed in the study concerned the opinion on bringing of natural souvenirs, lawfulness of such practices or harmfulness thereof to local tourist attractions (Table 1). As shown in Table 1, only 9.8\% respondents are opposed to bringing of natural souvenirs. Even fewer persons $(5.2 \%)$ claim such practices are unlawful, whereas $11.2 \%$ recognize their harmful effect on local tourist attractions.

Table 1. Natural souvenirs in the opinion of young tourists.

\begin{tabular}{lc}
\hline \multicolumn{2}{c}{ Questions and Percentage Structure of Answers } \\
\hline What is your opinion on bringing of natural souvenirs? \\
\hline I support such practices & $19.0 \%$ \\
I partially support such practices & $48.8 \%$ \\
I do not support such practices & $9.8 \%$ \\
I have no opinion & $22.4 \%$ \\
\hline Is acquisition of natural souvenirs lawful? & $10.7 \%$ \\
\hline Certainly yes & $71.2 \%$ \\
Depending on the kind of natural souvenir & $5.2 \%$ \\
Certainly not & $12.9 \%$ \\
I have no opinion & $11.2 \%$ \\
\hline Does acquisition of natural souvenirs by tourists cause any damage to local tourist attractions? \\
\hline Certainly yes & $30.0 \%$ \\
Rather yes & $36.7 \%$ \\
Rather not & $2.4 \%$ \\
Certainly not & $19.7 \%$ \\
\hline I have no opinion &
\end{tabular}

Source: Own study.

Subsequently, the study focused on the tourists who bring souvenirs, asking them whether these souvenirs include natural ones, i.e., ones originating from local nature, urban or rural architecture (e.g., shells, stones, parts of buildings, beach sand, volcano rocks, plants, animals, etc.): $61.4 \%$ of those surveyed were found to bring natural souvenirs from their trips. On the other hand, $38.6 \%$ respondents do not do it.

The following issue concerned the share of natural souvenirs among all souvenirs brought by tourists. For the highest percentage of tourists $(77.9 \%)$, they constitute a $\frac{1}{4}$ of all souvenirs. A greater share, amounting to $\frac{1}{2}$, was confirmed by $16.3 \%$ of the respondents. Few people (2.9\%) bring natural souvenirs only. An identical percentage (2.9\%) is comprised by tourists whose share natural souvenirs in the total number of souvenirs; it is found to be lower than $\frac{1}{4}$.

Moreover, it should have been explained what kind of natural souvenirs were preferred and taken by young tourists. Therefore, they were asked a question: "What kinds of natural souvenirs are you particularly interested in and which ones do you bring the most?" The structure of answers to this question was shown in Figure 1. It demonstrates that most tourists bring shells (53.9\%), stones $(22.7 \%)$, and seaside beach sand (18.0\%). Other kinds of natural souvenirs garnered less interest.

The motivation behind bringing natural souvenirs by young tourists are important as well. Figure 2 details the motivations and percentages of respondents who have invoked them. The sequence of major motivations for bringing of natural souvenirs is as follows: they are unique (26.2\%); genuine $(23.8 \%)$; bring back the best memories $(22.6 \%)$; and cannot be bought at a store $(14.5 \%)$. 


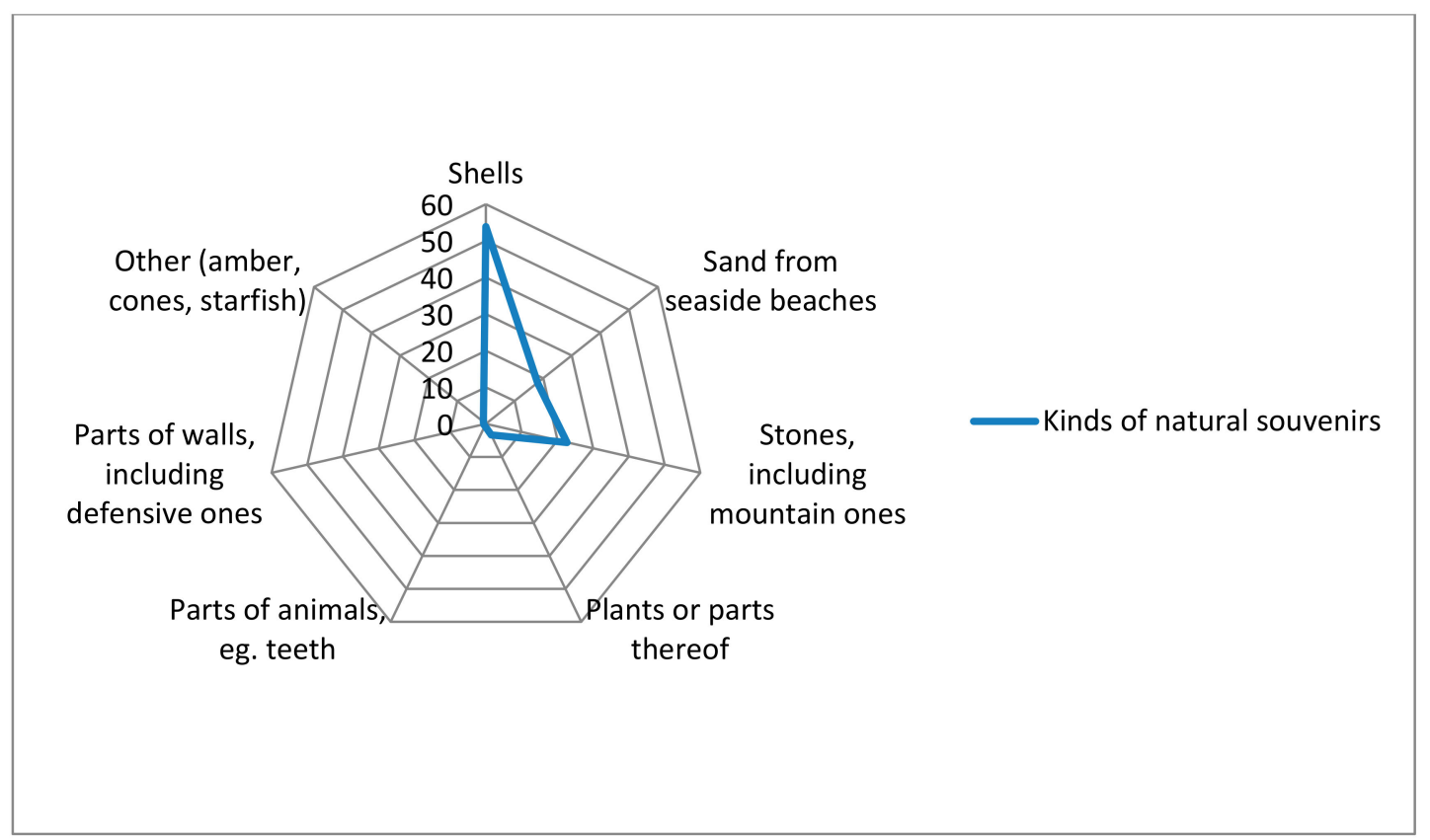

Figure 1. Kinds of natural souvenirs brought by tourists. Source: Own study.

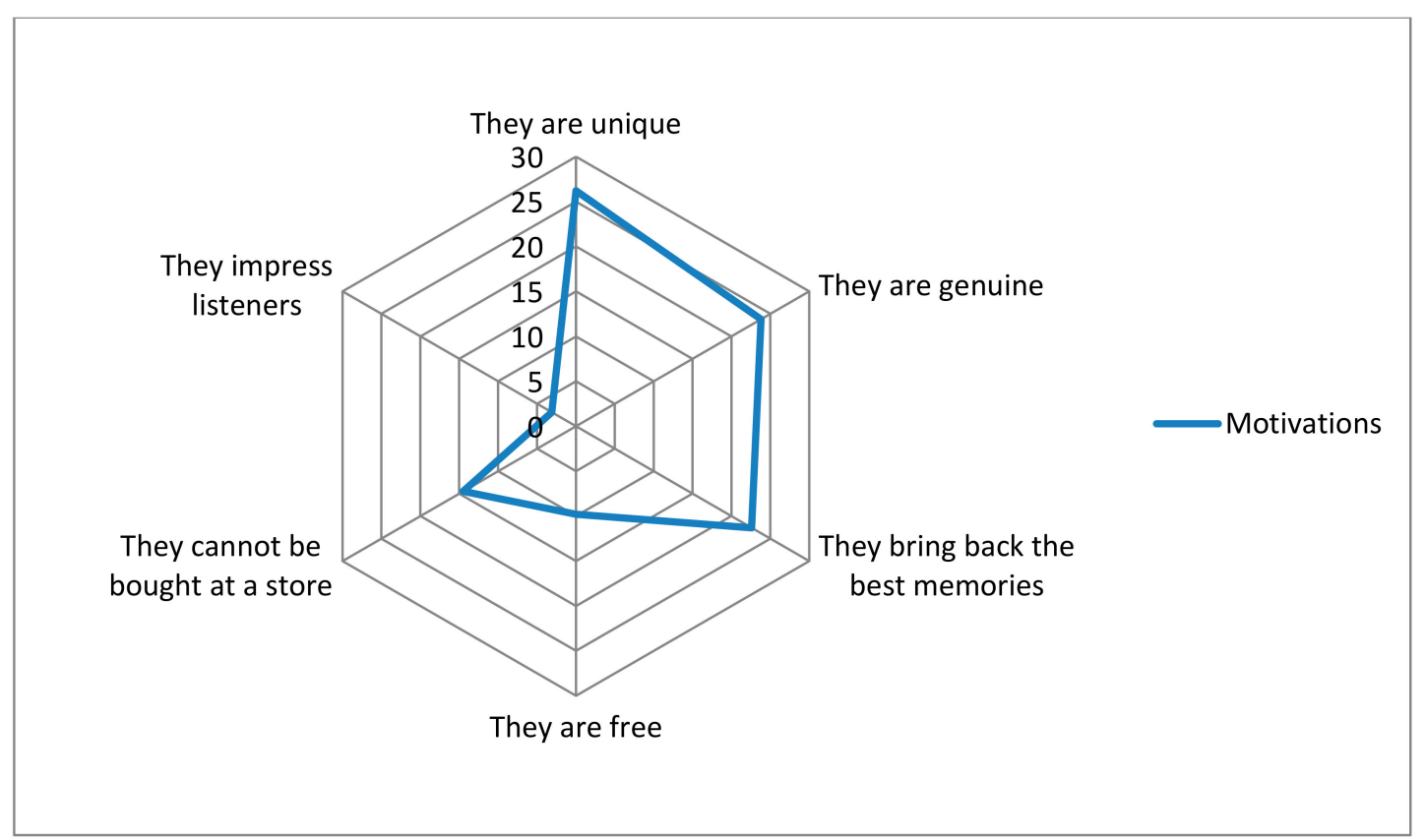

Figure 2. Reasons for bringing natural souvenirs. Source: Own study.

The final issue referred to the duration of storage of natural souvenirs. Most of the people surveyed $(76.4 \%)$ keep them for very long (never discarding such objects). Some respondents (18.3\%) discard natural souvenirs after several years. A small percentage does so after several months (3.4\%) or weeks $(1.9 \%)$.

\section{Demarketing of Natural Souvenirs}

The conducted research has shown that practices of acquisition and bringing of natural souvenirs are highly widespread among young tourists. Not only do they adversely affect the natural environment but they also cause dysfunctions in the social, cultural, and economic sphere. Therefore, curtailing of 
acquisition of such souvenirs is very important from the viewpoint of sustainability. Demarketing may play an important role in this process.

Demarketing of natural souvenirs is intended to discourage tourists from purchasing them and from acquiring them directly from the environment in which they find themselves. Natural souvenirs constitute parts of the nature and man-made buildings, but they can also be purchased in different points of sale, located in tourist destinations. Examples include numerous souvenir shops and stalls in the Mediterranean region. A considerable part of their assortment of commodities offered for sale include maritime fauna and flora in the form of shells, starfishes, sponges, seahorses, and many other products.

Demarketing of natural souvenirs should mainly be based on emotional messages inciting the feeling of fear, as well as factual messages. The feeling of fear will be caused by messages indicating the following issues connected with acquisition and bringing of such souvenirs:

(a) violation of the law and the related penalties;

(b) hazards to life and health, which may be caused by bacteria, viruses, fungi, and parasites found on natural souvenirs; they cause numerous diseases the symptoms of which manifest themselves either in the tourist's destination country or upon returning home.

Moreover, people need to be discouraged from bringing and collecting natural souvenirs through use of factual messages. They include figures and facts illustrating the deteriorating condition of the natural environment as well as losses in the area of material heritage of mankind. Acquisition of natural souvenirs comprising parts of the fauna or flora means extinction of many animal and plant species, which may, over time, cause disruptions in the functioning of ecosystems and threaten the existence of humans. Misappropriation of even minor parts of historic ruins, walls, or structures deprives them of their historic construction material, thus causing devastation of cultural heritage the originality of which cannot be restored using modern materials.

Messages discouraging tourists from acquisition of natural souvenirs may be disseminated in the following places:

(a) on websites and at offices of travel agencies;

(b) in tourist guides and offer catalogues of travel agencies;

(c) on websites and at offices of companies involved in booking of hotels and sale of tickets for different means of tourist transport, including airline tickets;

(d) at tourist accommodation sites (hotels, motels, boarding houses, guest houses, hostels, camping sites);

(e) in means of tourist transport (aeroplanes, coaches, trains);

(f) at border crossings;

(g) in media occupied with the subject matter of tourism (tourist magazines, tourist programmes, and channels on the television, radio shows, tourism in the Internet);

(h) at tourist sightseeing or leisure sites (boards placed at beach entrances, mountain trails, historic structures).

Natural souvenir demarketing messages may take different forms, typical of press, television, radio, and online advertising, as well as outdoor and indoor.

Implementation of demarketing of natural souvenirs is difficult for several reasons. First is the natural character and uniqueness of such goods. Many tourists prefer natural souvenirs over products of questionable aesthetic and quality, mass-produced, made of plastic materials, that dominate the offer of souvenir shops and stalls. Another serious barrier reducing the efficiency of demarketing of natural souvenirs is the fact they can be acquired free of charge, as well as emotional connection with the place of stay.

Utilization of demarketing of natural souvenirs requires creation and dissemination of messages with different content and forms. Such undertakings should be financed from two main sources: from 
the state budget as well as by owners of tourist attractions and leisure areas threatened by acquisition of natural souvenirs, since the goals of a state include protection of the natural environment and cultural heritage of the nation. On the other hand, it is in the interest of owners to maintain the value and attractiveness of leisure areas and historic objects managed by them.

\section{Conclusions}

The goal of this study was to identify the existing tendencies concerning bringing of natural souvenirs by the young generation of tourists in relation to the idea of sustainable development and sustainable tourism, as well as motivation, later utilization, and the state of awareness of the young generation concerning the scope of damage young people cause in the natural, socio-cultural and economic environment through this practice. The study was intended to explain whether the generation to follow has a tendency to aggravate or to mitigate ecological, social, and economic problems caused by acquisition of such souvenirs. An additional goal of the article was to indicate the essence and basic measures in the area of demarketing of natural souvenirs, which may discourage tourists from collecting them to a large extent.

The performed study has demonstrated that the practices concerning acquisition and bringing of natural souvenirs are very widespread among young tourists. Of $80.7 \%$ tourists who bring souvenirs from their trips, more than $60 \%$ own natural souvenirs. Moreover, $67.8 \%$ of tourists support or partially support bringing of such souvenirs, and $39.1 \%$ claim that these souvenirs are rather or definitely not harmful to local tourist attractions. It is also worth paying attention to a considerable number of persons with no attitude to such issues as: the opinion on bringing of natural souvenirs $(22.4 \%)$, the lawfulness of such practices $(12.9 \%)$, and the damage such souvenirs bring $(19.7 \%)$. The lack of opinion on these issues results from the unfamiliarity with legal regulations, as well as lack of or insufficient knowledge on the idea of sustainable development.

As the study has shown, the most popular among the brought natural souvenirs are shells $(53.9 \%)$, followed by stones $(22.7 \%)$, and sand from seaside beaches $(18.0 \%)$. This means that the natural environment, rather than historic objects, suffers most due to acquisition of such souvenirs.

Most tourists $(76.4 \%)$ keep their natural souvenirs for a very long time. However, even after a long time, regardless of their owner and place of storage, souvenirs always end up in landfills, causing other ecological problems.

The conducted research serves as a basis for formulation of final conclusions presented below:

- With regard to the natural environment, acquisition of natural souvenirs leads to depletion or even devastation thereof.

- With regard to the society, bringing of natural souvenirs also causes dysfunctions in the social sphere. Transport of such souvenirs from one end of the world to another also means transport of microorganisms or insects, which can lead to incidence and spread of diseases or, in extreme cases, to epidemics.

- In the cultural aspect, removal of parts of monuments of history, such as the Berlin Wall or azulejo tiles, causes losses in the material heritage of different countries.

- Taking of natural souvenirs also results in losses in the economic sphere of countries. The souvenir, crafts and manufacturing sector suffers losses. A loss is also caused to regions of tourist reception (places of stay of tourists) and tourist emission (places of origin of tourists). For instance, customs services can confiscate several tons of sand from tourists over one summer season. Constant depletion of sand necessitates replenishment, which is connected with financial outlays. On the other hand, costs of removal of natural souvenirs which are discarded and wasted over time are incurred in places of origin of tourists.

- In the ethical aspect, bringing of natural souvenirs constitutes a breach of the binding values, violation of the law, and of moral principles. Persons who bring natural souvenirs set a bad example to other tourists. 
To stem such negative trends, it is worth utilizing demarketing, based on emotional and factual messages. They should be disseminated in places with which a tourist comes into contact during preparations for the travel and during the travel itself. They may take diverse forms typical of press, television, radio, and online advertising, as well as outdoor and indoor.

Discouragement of tourists from bringing of natural souvenirs is a very difficult task for governments, tourist organizations, and tourism organizers. As the study has demonstrated, the following motivations prompt tourists to bring such souvenirs: natural souvenirs are unique $(26.2 \%)$, they are genuine $(23.8 \%)$, and they bring back the best memories $(22.6 \%)$. These are strong incentives, confirming the researchers' findings that a souvenir is connected with emotions and expresses the desire of search for authenticity. This is not just about the authenticity of appearance but also the authenticity of origin. Tourist also collect natural souvenirs because they are free. They do not have to be paid for, unlike souvenir products available at shops and stalls. Due to all of the above, many tourists may ignore appeals for abandonment of acquisition of natural souvenirs.

The present article examines the relevant and understudied subject matter of natural souvenirs in the aspects of sustainability, which is worth developing further by conducting research and discussions.

\section{Discussion}

The subject matter examined in the article prompts discussion concerning various aspects of collection of natural souvenirs and the directions of further research. The first issue is the significance of the problem of collection of natural souvenirs in the aspect of sustainability. At first glance, this problem may seem unimportant, since every tourist usually acquires small amounts of natural souvenirs, so the resulting ecological, socio-cultural, and economic damage is not large. We believe such perception of the problem is wrong. In our opinion, the problem is significant because modern tourism is characterized by mass nature and global scale, so collection of natural souvenirs is becoming a mass phenomenon as well. As shown by the research, more than $60 \%$ of tourists are aged 21-30 collect natural souvenirs. If we assume that such souvenirs are brought by a similar percentage of tourists from other age groups, we surely face a mass phenomenon here. A small amount of souvenirs per one tourist, multiplied by millions of people, gives enormous amounts, which results in serious damage. Therefore, it is advisable to conduct research concerning the share of the remaining age groups in bringing of natural souvenirs, as well as quantitative estimation of the scale of this negative phenomenon.

The phenomenon of acquisition of natural souvenirs contributes to devastation of the natural environment, thus bearing the attributes of a pathology in tourism. It also causes damage of social, cultural, and economic nature. Therefore, collection of natural souvenirs hinders sustainable development. Further research should explain in more detail what damage in the social, cultural and economic aspect is caused by collection of natural souvenirs. The authors of the present article claim that bringing of natural souvenirs causes exclusively damage in these aspects. This is the following subject to be discussed.

The problem of elimination of the phenomenon of acquisition and bringing of natural souvenirs requires further detailed research and analysis. The discussion should be focused on such issues as: how to influence tourists to make them renounce bringing of natural souvenirs? Is tightening of the law sufficient for this purpose? If it is, how to enforce legal prohibitions in practice? What other extra-legal means and forms of influence can be applied to discourage people from bringing of natural souvenirs?

An important problem, requiring discussion and further research, is consideration of the phenomenon of collection of natural souvenirs in the aspect of cultural, social, and economic differences between nations. In the opinion of the authors, the behaviour of tourists depends on their origin, i.e., on the cultural, social, and economic conditioning in their country. Further research should explain whether cultural, social, and economic differences impact the quantity and kind of acquired natural souvenirs.

Conducting of discussions and continuation of the research concerning acquisition, collection, and discarding of natural souvenirs will enable better understanding of the phenomena occurring in 
this area, including the behaviour of tourists. This will allow creation of increasingly sophisticated solutions for the purpose of limitation and, over time, complete elimination of such practices.

Author Contributions: Conceptualization, A.P. (Arnold Pabian); methodology, A.P. (Arnold Pabian); validation, A.P. (Arnold Pabian); formal analysis, A.P. (Arnold Pabian); investigation, A.P. (Aleksander Pabian); resources, A.P.(Arnold Pabian); data curation, A.P. (Aleksander Pabian); writing-original draft preparation, A.P.(Aleksander Pabian); writing-review and editing, A.P. (Aleksander Pabian) and A.B.; visualization, A.B.; supervision, A.P. (Arnold Pabian); project administration, A.B.; funding acquisition, A.P. (Arnold Pabian). All authors have read and agreed to the published version of the manuscript.

Funding: This research received no external funding.

Conflicts of Interest: The authors declare no conflicts of interest.

\section{References}

1. Rapczyńska, I. Bricks, Teeth and Barbed Wire, or Unusual Holiday Souvenirs. 2016. Available online: https: //turystyka.wp.pl/cegly-zeby-i-drut-kolczasty-czyli-nietypowe-pamiatki-z-wakacji-6044419818861185a? ticaid $=117 \mathrm{~b} 1 \mathrm{~d}$ (accessed on 20 February 2018).

2. Swanson, K.K.; Timothy, D.J. Souvenirs: Icons of Meaning, Commercialization and Commoditization. Tour. Manag. 2012, 33, 489-499. [CrossRef]

3. Gordon, B. The Souvenir: Messenger of the Extraordinary. J. Pop. Cult. 1986, 20, 135-146. [CrossRef]

4. Brennan, L.; Savage, T. Cultural Consumption and Souvenirs: An ethical framework. Arts Mark. Int. J. 2012, 2, 144-160. [CrossRef]

5. Wilkins, H. Souvenirs: What and Why We Buy. J. Travel Res. 2010, 50, 239-247. [CrossRef]

6. Paraskevaidis, P.; Andriotis, K. Values of souvenirs as commodities. Tour. Manag. 2015, 48, 1-10. [CrossRef]

7. Shtudiner, Z.; Klein, G.; Zwiling, M.; Kantor, J. The value of souvenirs: Endowment effect and religion. Ann. Tour. Res. 2019, 74, 17-32. [CrossRef]

8. Haldrup, M. Souvenirs: Magical objects in everyday life. Emot. Space Soc. 2017, 22, 52-60. [CrossRef]

9. Löfgren, O. Scenes from a Troubled Marriage: Swedish Ethnology and Material Culture Studies. J. Mater. Cult. 1997, 2, 95-113. [CrossRef]

10. Collins-Kreiner, N.; Yael, Z. Tourists and Souvenirs: Changes through Time, Space and Meaning. J. Herit. Tour. 2011, 6, 17-27. [CrossRef]

11. Soukhathammavong, B.; Park, E. The autentic souvenir: What does it mean to souvenir suppliers in the heritage destination. Tour. Manag. 2019, 72, 105-116. [CrossRef]

12. Littrell, M.A.; Anderson, L.F.; Brown, P.J. What makes a craft souvenir authentic? Ann. Tour. Res. 1993, 20, 197-215. [CrossRef]

13. Hitchcock, M.; Teague, K. Souvenirs: The Material Culture of Tourism; Routledge: Oxon, UK; New York, NY, USA, 2019.

14. Hume, D.L. Tourism Art and Souvenirs; Routledge: New York, NY, USA; London, UK, 2014.

15. Han, H.; Kiatkowskin, K.; Ryu, H.B.; Jung, H.; Kim, W. Determinants of young vacationers' recycling and conservation behavior when traveling. Soc. Behav. Personal. Int. J. 2019, 47, 1-11. [CrossRef]

16. Han, H.; Yu, J.; Kim, H.-C.; Kim, W. Impact of social/personal norms and willingness to sacrifice on young vacationers' pro-environmental intentions for waste reduction and recycling. J. Sustain. Tour. 2018, 26, 2117-2133. [CrossRef]

17. Han, H.; Kim, W.; Kiatkawsin, K. Emerging youth tourism: Fostering young trevelers' conservation intentions. J. Travel Tour. Mark. 2017, 34, 905-918. [CrossRef]

18. Bo, M.; Ryu, H.B.; Chua, B.-L.; Han, H. Predictors of intention for continuing volunteer tourism activities among young tourists. Asia Pac. J. Tour. Res. 2020, 25, 261-273.

19. Anastasiadou, C.; Vetesse, S. From souvenirs to 3D printed souvenirs. Exploring the capabilities of additive manufacturing technologies in (re) framing tourist souvenirs. Tour. Manag. 2019, 71, 428-442. [CrossRef] 
20. Sthapit, E. The more the merrier: Souvenir shopping, the absence of choice overload and preferred attributes. Tour. Manag. Perspect. 2018, 26, 126-134. [CrossRef]

21. Swanson, K.K.; Horridge, P.E. Travel motivations as souvenir purchase indicators. Tour. Manag. 2006, 27, 671-683. [CrossRef] 